\title{
Experiential Learning in Graduate Education: Development, Delivery, and Analysis of an Evidence-Based Intervention
}

\author{
Samantha M. Harden, Kacie C. Allen, Clarice N. Chau, \\ Serena L. Parks, Ashley L. Zanko \\ Department of Human Nutrition, Foods and Exercise, Virginia Tech, Blacksburg, USA \\ Email: harden.samantha@vt.edu
}

Received July 11 ${ }^{\text {th }}, 2012$; revised August 15 ${ }^{\text {th }}, 2012$; accepted August 30 ${ }^{\text {th }}, 2012$

\begin{abstract}
Certain expectations are outlined for a young professional with a recently earned doctoral degree. In academia, it is anticipated that graduates will demonstrate the ability to obtain funding, actively engage in an interdisciplinary work environment, and value experiences with critical thinking and problem solving. This paper outlines a unique learning experience of five graduate research students who progressed from the initial stage of research question conceptualization to dissemination of research results. The process included a written research design proposal, grant review process, physical activity program development, intervention delivery, data analysis, and publication of findings. Challenges overcome by these young investigators throughout the research process (i.e., intervention recruitment, development and delivery) are included within the manuscript, as well as other important findings from this process evaluation. The first-hand account of their learning experiences demonstrates the value of promoting internal competition (i.e., within a department, college, university), while working as a collaborative research team to prepare graduate students for "real-world" research and work-related scenarios. Graduate student faculty mentors should incorporate more opportunities for their students to glean research experience described here.
\end{abstract}

Keywords: Graduate Education; Experiential Learning; Process Evaluation; Research Reflexivity

\section{Introduction}

In the realm of education, experiential learning boasts as one of the foremost sciences (Bransford, Brown, \& Cocking, 2000) in which students may learn through a process rather than placing the majority of emphasis on outcomes (Dewey, 1897). The post-higher education job-market expects candidates to have developed reflective and collaborative skills (Hanrahan \& Isaacs, 2001; Tsang, 2011). Contemporary pedagogy advises that students should learn through interactive, inquiry-based teaching and learning environments (Moore, Fowler, \& Watson, 2007; Moore, Tatum, \& Sebetan, 2011) based on the complexities of the twenty-first century society (e.g., technology, multiculturalism, diversity, and globalization). These varied experiences will prove to be invaluable in the work-field and real-world settings. It is understood that people learn complex materials when the learning process is an active one rather than a simple knowledge transfer from teacher to student (Bransford et al., 2000). Yet, for the most part, pedagogical practices are still didactic (i.e., lecture-based) and antiquated.

However, this can change, with one assignment that inspires a department, exhilarates a college, influences the university at large, and thus, sparks a transformation in learning. While many learner-centered pedagogical approaches clearly outline the details for undergraduate students, the research on appropriate graduate education measures is less abundant. Recent twenty-first century-based changes have occurred in graduate curricula. The outcomes of a doctoral degree include meeting the expectations of job calls: development of sound, theory-based interventions, train and mentor students, obtain and manage extramural funding, design an evidence-based program and implement it as such, and publish the findings. These skills are integral to a high level of success in academia. Unfortunately, there is criticism that those who earn a doctoral degree are often not meeting work expectations (Barnett \& Coate, 2005; Gaff, 2002), as the skill-sets built through different doctoral programs within and across university settings are varied and unstandardized.

The purpose of this paper is to discuss the experiential process provided to junior research scientists at Virginia Tech, within the Translational Obesity Research Program (TORP) of the Department of Human Nutrition, Foods, and Exercise. This fellowship provided five graduate students with funding for a 2-group randomized control trial (RCT) to increase physical activity (PA) among Black college women.

\section{Grant Review Process}

\section{Grant Proposal}

As argued above, graduate education curricula do not necessarily develop the skills students will actually need to be competitive in tenure-track, research driven positions. Therefore, this experiential opportunity focused on simulating the grant proposal process. The team of young investigators developed and submitted a grant proposal. This proposal then underwent review utilizing National Institutes of Health (NIH) processes and requirements, including revisions and resubmission. Once awarded, the investigative team then had to manage funding, obtain IRB approval, develop and deliver the intervention content, collect data, and analyze the results. Along the way the team reported current project status and plans for dissemination to their funders. 


\section{Proposal Development and Review}

To begin the fellowship, the funders (i.e., faculty advisors within the TORP lab) issued a call for proposals with the aim of objectively measuring physical activity (PA) using accelerometers. Students were slow to respond due to "poor timing," expressed as potential scheduling conflicts due to coursework and various other commitments. The point exactly: can anyone in academia identify a time in which a call for proposals was released when there were no other conflicts of time or interest? Students were better able to understand this underlying message when faculty members explained this perspective. Thus, students continued to develop their proposal, and experienced the importance of time management when working on several academic/research related projects at one time. This explanation is of particular importance to contemporary students who are known to respond positively when faculty members communicate the overarching lesson.

$\mathrm{NIH}$ grant submission guidelines provided a model for the grant proposal. In "Demystifying the NIH Grant Application Process,” Berg and colleagues (2007) provide valuable insight to successful grant applications. First, they suggest familiarizing oneself with previously accepted grants and determining the appropriate funding mechanism; then developing a collaborative team. Key dialogue with a collaborative research team assists in the iterative process that is "grant writing." The research team was able to ensure that their proposal was compatible with the specific call (i.e., to use accelerometers as an outcome measure). The young investigators interested in applying for the fellowship met to discuss their research backgrounds and all contributed to the submitted proposal.

\section{Submitted Proposal}

The submitted proposal was a $2 \times 2$ group RCT as seen in Figure 1 below. The purpose of the proposed study was to determine 1) the effectiveness of a group dynamics-based PA promotion program could increase minutes of PA for Black college women and 2) the extent to which group based or individually based incentives. Group dynamics-based PA promotion programs are based on Carron \& Spink's (1993) team building model that posits that group structure (i.e., roles), group environment (i.e., developing a sense of distinctiveness), and group processes (i.e., group goal setting) ultimately increase the participant's perception of group cohesion. Group cohesion is the idea that group members will stick together and remain united towards their task (Carron, Widmeyer, \& Brawley, 1998). A greater perception of group cohesion has been linked with increased attendance and compliance with exercise prescription. Group cohesion is, then, the strongest predictor of
PA behavior change (Estabrooks, 2000; Golembiewski, 1962; Lott \& Lott, 1965).

In the first condition of the group dynamics-based intervention, compensation was based solely around assessment and program supplies. If an individual completed all assessments, they could earn twenty-eight dollars, and receive the IMA DIVA T-shirt and weekly session supplies. The next arm was a group dynamics-based and compensation at the group level, based on group goal setting and group attendance. The intervention arm would have cohorts $(n=4)$ within the session (i.e., four smaller groups within the larger meeting), which were designed to facilitate group goal setting. The facilitators would assist in appropriate group goal setting to develop attainable goals to meet the American College of Sports Medicine's PA guidelines, while re-directing groups away from unreachable PA goals. The team with the highest percentage of goal completion would win a nominal award for winning that week's challenge. Team goal setting would be reestablished midway through the program (week 4), after the first round of incentives. The third condition would include group dynamics-based PA sessions, with compensation for individual goal setting and individual attendance. Group discussion, as outlined above, was to yield a collaboratively set goal, as well as individual goals. Within this intervention arm, the participant who achieved the greatest PA percentage and the participant with the highest attendance would receive the monetary incentive for that week. Finally, the fourth group would receive compensation for both individual and group goal setting and attainment. The group with the highest percentage of goals attained would receive an incentive based on the points system. In addition, whomever had the highest percentage achieved of their individual goal and greatest attendance would receive a monetary incentive.

\section{Lessons Learned from Grant Submission}

In the grant review process of the proposals submitted, four faculty members and one senior graduate student independently scored abstracts following NIH criteria (overall impact, significance, investigators, innovation, approach, and environment) and identified key strengths and weaknesses of each proposal. Students sat in on a mock NIH study section, while their proposals were discussed amongst the reviewers. In the mock grant review session, faculty members provided further feedback and dialogue on the proposed studies. The proposal with the best combined score from reviewers was awarded the fellowship. While it is not common for grant authors to be present during reviews, the audible and written feedback served as a learning experience for the students, useful for the development of future grant proposals. General strengths of the proposal were: a RCT research design, defined measures, a group-based ap-

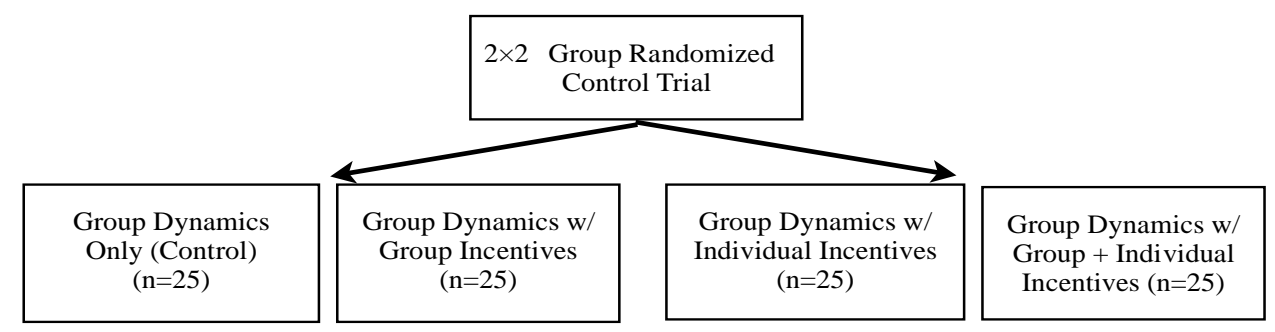

Figure 1.

Proposed $2 \times 2$ group randomized control trial. 
proach, and a significant target population. Weaknesses to be addressed included unclear incentive distribution and unclear distinction between research groups. Hearing about the strengths and weaknesses of the proposal was a critical learning experience because the young investigators were able to hear inquiries about outcomes/directions that they had not previously considered. Overall, this was a humbling experience for the young investigators to witness and absorb the seemingly harsh critique of their proposals by the reviewers.

\section{Revise and Resubmit}

Based on the feedback received by the funders, and the potential setback in recruiting 100 women, the research design was changed to a 2-group RCT as seen in Figure 2. The revised primary specific aim was to determine the effectiveness of a group dynamics based PA program in the target population of young adult (i.e., 18 - 25 years old), Black, college women.

Within the group dynamics intervention arm, participants were assigned to small groups (i.e., teams of five) to remain in for the duration of the program. Within these small groups, the facilitators were able to integrate interaction and communication, foster friendly competition as well as accountability, and develop a sense of distinctiveness (i.e., team names). The facilitators also led collaborative, self-selected group goal setting within the intervention arm. These strategies and principles, applied within the group dynamics intervention arm, served to increase the participant's perception of group cohesion (Estabrooks, 2000).

Group cohesion is a predictor of PA program attendance and adherence (Estabrooks, 2000); therefore, each session was designed to target the dimensions of group cohesion [i.e., individual's attraction to the group's task (ATG-T), individual's attraction to the group socially (ATG-S), the group's integration towards the task (GI-T), and the group's integration socially (GI-S)]. Beginning with the first session, participants engaged in activities that increased the perception of group cohesion, such as completing a timeline of their lives that included thoughts and behaviors regarding PA. The sessions were also designed with specific attention to cultural issues, values, and experiences. For example, one class session addressed common hair concerns (i.e., barrier) for this specific population when engaging in PA.

Participants in the second condition were assigned to matched-contact control group, where they engaged in PA in sessions modeled similar to typical gym classes (i.e., no facilitated group-based strategies). Trained facilitators led the weekly, 1-hour group sessions. Sessions outlined as above, except the program components (i.e., relay races) were delivered to aggregates. This meant participants were placed into various groups throughout the program and facilitation was

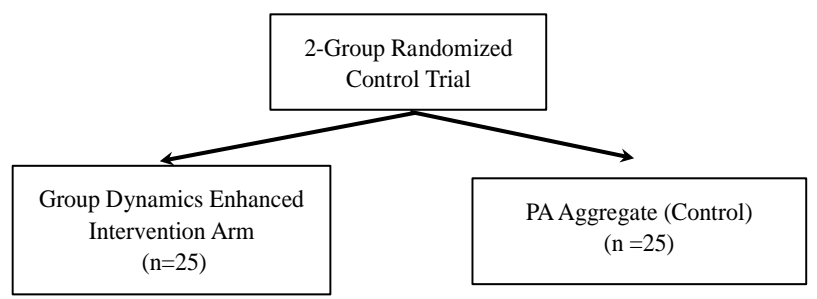

Figure 2.

Delivered research design. around PA rather than increasing cohesion (i.e., interaction and communication around common barriers). The research team met regularly to discuss the ongoing processes of the intervention delivery, while noting necessary on-the-spot adaptations. Following the grant review process, students addressed reviewer comments and further sought advice and expertise from senior research personnel.

\section{Program Implementation}

\section{Program Summary}

The research team developed an acronym for the program [IMA DIVA (Increased Movement in African Diaspora Individuals of Virginia)]. This served to signify that the program was meant for women and to align with temporally relevant use of the term "diva" as a positive, rather than negative, depiction of women. IMA DIVA was inspired by the popularity of popular-culture singer Beyoncé's song entitled, "Diva," and became the unifying, up-beat theme song for the project. The program was 8-weeks in duration, as previous 8-week long PA interventions have proven effective (Doak, Visscher, Renders, \& Seidell, 2006), with both post-intervention and 3-month follow-up assessments. Each week, participants engaged in onehour sessions, enhanced with evidence-based activities. The total time in sessions was 8 hours with additional intervention contacts. Each week, participants received reminders about the time and location of the session by email (one day before the session) and phone (two-hours before the session). These total contacts were approximately five minutes per week, for a total of 40 minutes for each condition. During the first session, participants were also given a hand-bill outlining all the information above (i.e., time, location, on-campus and off-campus PA resources). Participants were encouraged to perform 30 minutes of moderate intensity activity five times per week and to incorporate two days of strength training according to the current adult PA recommendations (CDC, 2011). Class sessions provided a variety of activities on how to meet these recommendations (i.e., resistance bands, Zumba, abdominal work-outs, relays). The research team developed a program manual to ensure delivery fidelity. Additionally, a post-program focus group was conducted to gain valuable feedback from participants for strengthening program delivery and utility. The Virginia Tech Institutional Review Board approved all study activities and survey instruments.

\section{Role Clarity}

After receiving the fellowship, the students discussed role clarity to ensure individual student ownership and primary responsibility of specific project tasks. All members of the team had previous research experience; however, roles were assigned based on an assessment of individual strengths. The research team consisted of a principal investigator (Ph.D. candidate with expertise in group dynamics), a project manager (Master's student with organizational skills), a recruitment agent (Ph.D. student with access to the target population), a retention strategist (Ph.D. student with experience tracking participants), and a data manager (Ph.D. student with a Master's degree in statistics). These roles were associated with responsibilities of 1) intervention design, session delivery, overall project management; 2) administrative duties, budget, incentives; 3) development distribution and presentation of recruitment materials; 4) 
participant tracking, retention efforts, data collection; and 5) data entry, management, analysis.

\section{Recruitment and Retention}

The collaborative research team developed a strategic plan for recruitment. Using previously effective methods, the team decided on a multi-strategy approach. First, the research team established the eligibility criteria, which was relatively inclusive as to increase representativeness (Dzewaltowski, Estabrooks, \& Glasgow, 2004). The targeted population consisted of African Diaspora women enrolled at the Virginia Tech's Blacksburg campus in rural Southwest, Virginia. The sample eligibility criteria included being enrolled in at least 3 credit hours, 18 - 25 years of age, and self-identification as a Black female. Non-English speaking women and those who had physician contraindications to PA were excluded. Table 1 indicates both the planned strategies, as well as those that were actually implemented.

\section{Planned Recruitment Strategies}

The strategic plan for recruitment included word of mouh, culturally appropriate flyers posted around campus, mass emails to targeted listservs, and presentations at organizational meetings, with audiences consisting primarily of the target population. Using targeted listservs, the research team planned to present recruitment sessions at all student organizations that were identified as primarily focusing on minority populations. Interested persons who requested more information about the study were to be contacted within 48 hours of initial contact. These individuals were provided study details, consent form, and demographic screener. If an interested person did not return the consent form or demographic screener within two weeks of initial interest, the contingency plan was to first send an email and then make a phone call.

\section{Implemented Recruitment Strategies}

Due to the timing of the recruitment which occurred at the end of the Fall semester just prior to Winter break, only five out of 23 planned recruitment sessions at organizational meetings occurred. These presentations provided real-world experience to answering program inquiries, consenting multiple parties, and administering surveys. At times, the presidents of student organizations were unresponsive. After speaking with funders, the research team was advised to contact advisors of student organizations directly. Upon receiving advice from funders, the recruitment team emailed advisors of the unresponsive organizations. To help with recruitment, emails were sent from a faculty member of the target population who had access to emails of the target population. Even though the research team planned to follow-up with participants via phone calls; this proved challenging as many interested persons did not provide phone numbers. Thus, email was the only reliable way to contact individuals.

\section{Lessons Learned in Recruitment}

The recruitment team learned that sometimes it is not the intensity of recruitment, but that the timing is more important. In the Fogg Behavior Model, timing is a critical element that is often missing from behavior change (Fogg, 2009). To overcome statistical power issues, the research team anticipated recruiting 100 people. Though recruitment lasted three months, it began toward the end of the fall semester (November) and ended after the first three weeks of the spring semester (early February). By the time recruitment started, some organizations had already held their last monthly meeting and/or many students were preparing for end of semester assignments and final exams. Additionally, participants that signed up at the beginning of recruitment may have lost interest due to the lag time for the intervention start date. Thus, even though potential participants may have been aware of the study through various mediums, they may have chosen not to participate due to the timing and competition with academic and/or personal demands. One final critique for recruitment was the data obtained from the initial screener. The screener only included information on demographics, which may have lead to the recruitment of a population that was more active than the initial desired population (i.e., sedentary or insufficiently active Black college women). Essentially, the screener, or specifically the lack of PA information available from the screener, led the researchers to recruit a large proportion of participants who were already meeting PA recommendations.

\section{Planned \& Implemented Retention Strategies}

The research team also devised a retention strategy a priori to the intervention. Strategies were presented at an initial team meeting and revamped accordingly (see Table 2). To facilitate program retention, the strategic plan was to remind participants about upcoming sessions via email the day before each session and encourage continued participation among those who were no longer interested in the program. These strategies were im-

Table 1.

Planned and implemented recruitment strategies.

\begin{tabular}{|c|c|}
\hline Planned Recruitment Strategies & Implemented Recruitment Strategies \\
\hline Flyers in academic buildings and residential halls & Executed as planned \\
\hline Recruitment sessions at most/all student organization meetings & Recruitment sessions at few student organization meetings \\
\hline Project recruitment sessions at 23 organizational meetings & 3 organizational recruitment sessions \& additional recruitment sessions in residential halls \\
\hline Recruitment emails to listservs & $\begin{array}{l}\text { Recruitment emails to listservs + email from faculty member with access to emails of target } \\
\text { population }\end{array}$ \\
\hline In initial contact get phone number and email & Only emails received, no phone numbers \\
\hline Recruitment follow-up protocol & Additional follow-ups for unresponsive individuals \\
\hline Recruitment emails to Presidents of student organizations & Recruitment emails to Presidents and/or advisors due to delayed/unresponsive to emails \\
\hline
\end{tabular}


plemented as planned. However, another program retention strategy was to call participants at least two hours in advance. This strategy was not consistently implemented due to time demands of calling all participants within the proposed time period. During focus group interviews, some participants stated that the timing of their call was acceptable, while others stated that calls were not critical, as they had already received an email reminder the day before. The two remaining strategies that were not implemented as planned were primarily teambased and included the timing of updating attendance sheets, emailing participants regarding absences, and executing the three month follow up. The research team was not able to update the attendance sheets as quickly as planned due to the additional time demands associated with validating attendance. In order to validate attendance, the research team had to review the completion of survey assessments as some participants arrived late, missing the sign-in sheet. Lastly, the research team was not able to distribute data collection instruments during the week planned due to resource sharing with an intra-lab study. Three month data collection was then off by one calendar week.

\section{Implementation Fidelity}

\section{Planned \& Implemented Sessions}

The program manual created by the research team outlined activities, to be conducted in each session, based on the underlying theoretical components of group dynamics (see Table 3). For the intervention arm, each week included an "ambitious girls" friendly competition related to with nutritional facts or PA competitions (i.e., relay race). To enhance the effect of this challenge, the winning team was always given a nominal award (i.e., water bottles, gym towels). The women were also asked to sit in their small groups and engage in task-oriented communication around PA goals. The research team also conducted activities, such as a physical activity and healthy eating timeline, which allowed the participants to explore the existence of deeper similarities (i.e., hometown location, sports played in high school). Small groups were limited to five participants in order to increase the likelihood of interaction and communication. The control group was to meet for the same duration and frequency as the intervention arm. However, the session outlines were created for the facilitators to provide information on appropriate individualized goal setting, nutritional facts, and a special 'Size Healthy' presentation that highlighted fitness versus fatness. The participants in the control group were also scheduled to engage in the same duration of PA as the intervention group.

Implementation fidelity, according to the original RCT design, was slightly altered, mostly due to intervention drift. One potential influence on drift was distributing the IMA DIVA shirts to all participants, rather than simply the intervention condition. The original intent was to use the t-shirts as compensation for participation for all. The facilitators then encouraged the participants in the intervention group to wear their new t-shirts to the sessions and at the gym to create a sense of distinctiveness within the intervention group. However, in both conditions, participants wore the shirts to sessions and around campus. Furthermore, the influence of friendly competition may have been compromised. The intervention condition had predetermined small groups that competed weekly and received incentives. In the control condition, facilitators randomly assigned groups (i.e., chosen by counting off in height order) to engage in similar physical activities as the intervention arm. While the groups in the control arm were approximately 12 participants versus 12 participants, friendly competition still ensued as the women cheered on their teammates. Finally, when facilitating individualized goal setting in the control arm, the participants organically wanted to share advice and tips with

Table 2.

Planned and implemented retention strategies.

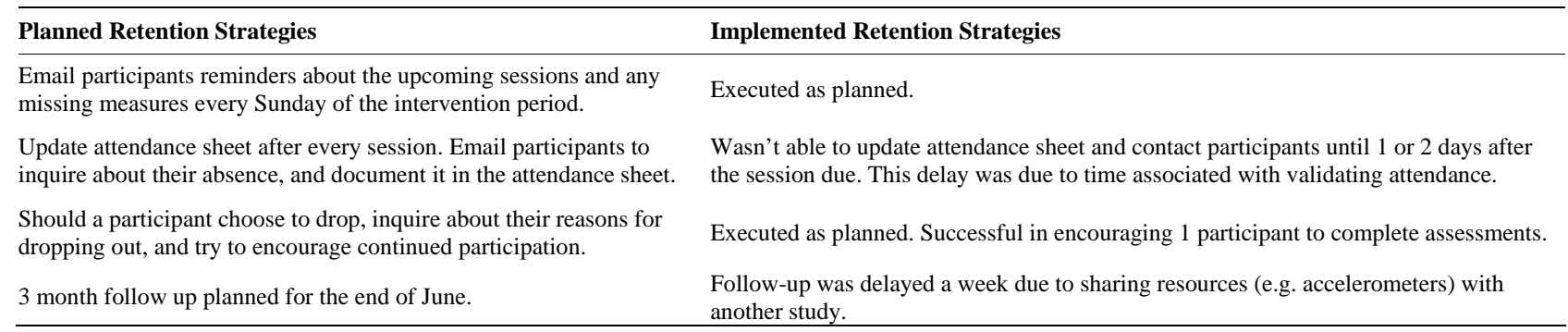

Table 3.

Planned and delivered implementation components.

\begin{tabular}{ll}
\hline Planned Implementation & Delivered Implementation \\
\hline Intervention Arm & Intervention Arm \\
Group Dynamics [Strategies \& Principles] & Group Dynamics [Strategies \& Principles] \\
Friendly Competition & Friendly Competition \\
Facilitated Interaction \& Communication & Facilitated Interaction \& Communication \\
Group Goal Setting & Control Arm \\
Feedback on Group Goals & Matched Contact Control \\
Group Distinctiveness & Didactic Nutrition and Physical Activity Lessons/Information \\
Control Arm & Individualized Goal Setting \\
Matched Contact Control & Group Distinctiveness \\
Physical Activity Aggregate & Friendly Competition \\
Didactic Nutrition and Physical Activity Lessons/ Information & Interaction \& Communication \\
Individualized Goal Setting & \\
\hline
\end{tabular}


other participants on how everyone could achieve their goals; this led to an increase of interaction and communication. A specific example of this can be seen in one participant offering to teach a few other participants how to swim at the pool on campus (i.e., outside of class time). While the intent of the delivered research design was to determine the influence of group dynamics in this specific population, the true comparison ended up being between group-dynamics based PA sessions delivered to small groups versus large groups.

\section{Lessons Learned in Implementation Fidelity}

Due to lower attendance rates in the intervention group, the small group composition changed frequently. In other words, if a participant came to the intervention session and her group members were not present, the facilitator placed her in an existing group for the duration of that session. This adaptation deterred from the longitudinal effects of small group design. Additionally, two of the key components of behavioral interventions grounded in group dynamics are group goal setting and feedback loops (i.e., facilitator feedback). However, the groups' self-selected goals were not necessarily PA behavior based (i.e., minutes of physical activity, attendance), but more socially based (i.e., meeting with group members for dinner). Intervention drift was also seen as the "aggregate" of 25 women organically (and enthusiastically) engaged in friendly competition and encouraged each other with verbal and physical cues of support.

\section{Measures}

The program was evaluated through a mixed methods approach using validated and reliable self-reported questionnaires as well as focus groups. Members of the research team had varying levels of experience in both quantitative and qualitative data collection and analysis.

Quantitative outcomes were measured at baseline before the start of the program, immediately after the program ended, and 3 months after program completion. Validated and reliable self-reported questionnaires measured health-related quality of life (CDC), PA self-efficacy and self-regulation (Anderson, Wojcik, Winnett, \& Williams, 2006), deep and surface level similarities (Beauchamp, Dunlop, Downey, \& Estabrooks, 2012) and group dynamics through the Physical Activity Group Environment Questionnaire (Estabrooks \& Carron, 2000). PA was measured subjectively with the modified Godin Leisure-Time Exercise Questionnaire (Godin \& Shephard, 1985) and objectively with Actigraph GT3X triaxial accelerometers (Sasaki \& Freedson, 2011). Participants wore accelerometers for one week at each data collection period and kept a log of the hours they wore the device, indicating the time periods they engaged in exercise. All responses to the validated questionnaires were entered into PASW 18.0. Means scores for key variables were calculated at each data collection point. Paired sample t-tests detected any mean differences of outcomes by group enrollment between baseline and post-program, while linear regression sought to detect predictors of PA change over the course of the program. Due to the dynamic nature (i.e., sporadic attendance) of the intervention group, it was difficult to obtain consistent data throughout the intervention. In the final sample, there were 24 participants randomized to the control group and 20 to the intervention group, indicating a small sample size with low statistical power. Additionally, while the attrition rates were low, due to the small sample size, it was difficult to defect any statistically significant changes of the measured variables.

The research team also used predetermined semi-structured interview questions to obtain data on recruitment, retention, feedback on implementation, and potential program sustainability. Each focus group was led by two novice moderators and an experienced co-moderator. This opportunity allowed novice moderators to experience common focus group interactions, such as leading through awkward silences, controlled responses to positive feedback (i.e., avoid leading), encouraging participation from all attendees, adjusting to and avoiding tangents, and time management. After the conclusion of both focus groups, two trained young investigators independently transcribed the focus group discussion verbatim. A senior member of the research team reviewed each transcription for accuracy and requested the revision of one transcription. Reviewing the transcriptions taught the senior member and one of the young investigators the importance of carefully selecting transcribers and paying attention to detail, in order to avoid repetition of transcribing. Approved transcripts were independently coded for meaning units. Analyzing the focus group data provided opportunities for mentorship of the young investigators and the opportunity to apply classroom-based knowledge and experience on a larger scale. While coding, researchers made conscious efforts to code transcripts with minimal bias. The experience taught researchers that qualitative data may not support the theoretical framework of an intervention, but is still informative. Researchers were able to identify themes that provided feedback for structure, content, and delivery.

\section{Analytical Plan}

As set by the a priori hypothesis, the enhanced group dynamic arm would show more changes in the measures than the control group. Therefore, the first round analysis sought to detect changes in all variables outlined in Table $\mathbf{4}$ between post-program and baseline by a paired sample t-test. However, analysis revealed more significant changes in the control group than in the enhanced group dynamics group, contradicting the hypothesis. After the 3-month follow up data collection, the same paired sample t-test between post-program and follow-up sought to detect significant changes in measured variables between the two groups. Again, there were no statistically significant changes in minutes of physical activity, indicating that there was no measured difference between the conditions that effected outcome measures. Therefore, a different data analysis was approached to try to detect statistical significance by group membership. In this new regression model, we sought to the determine PA change (e.g., the dependant variable) based on the variables of group membership, group similarities, group dynamics, and total class attendance (e.g., the independent variables).

To satisfy the objective of the specific grant call (e.g., use accelerometers as an outcome measure), data from accelerometers worn by the participants were extracted at each data collection period (i.e., baseline, post-program, follow-up). An ActiGraph GT3X triaxial accelerometer measured activity at 60 second epochs on the vertical, antero-posterior (AP), and vector magnitude (VM) axes. The research team learned that the initial Freedson cut points (Freedson, 1998) used to determine intensity of physical activity were outdated on the triaxial acceler- 
ometers, and used suggested new cut points instead (Sasaki \& Freedson, 2011). Aggregate minutes of physical activity were calculated by intensity category. However, since current research is inconclusive on the best practices for using triaxial accelerometers, the data collected on the accelerometers were not included in further analyses and did not contribute to the overall outcomes (Sasaki, 2011; Trost et al., 2011).

\section{Results}

When combining both moderate and vigorous self-reported minutes of PA, both the control and the enhanced group were meeting the PA recommendations of 150 minutes per week (Table 5). Participants in the control group increased their post-program PA by almost an hour (i.e., 58.6 minutes). However, by the 3-month follow-up, the control group was engaging in less PA than they were at baseline by 76 minutes. The group dynamics-based intervention arm increased physical activity by 84 minutes from baseline to the post-program follow-up. By the 3-month follow-up, the group dynamics-based intervention arm had still increased from baseline, by 48.8 minutes. However, none of these increases were significantly different between the intervention and control group. Also, as depicted in Table 5, the standard deviations for both groups were very large.

\section{Discussion}

While the proposed and implemented study did not have the predicted outcome of increasing total minutes of PA for the intervention arm, programmatic, evaluative, and real-world adaptation lessons were learned by the five graduate students involved in the planning and implementation of the program. From the beginning of the experiential learning process, students learned invaluable feedback from the grant review (i.e., research design is strong, but some programmatic adaptations should be made), to successful recruitment strategies for a population that was dispersed across a large university, and the use of technology (i.e., text, E-mail) for retention strategies. The most significant lessons learned surrounded obtaining and analyzing data as well as drift of intervention components.

As seen throughout the paper, the researchers were proponents of group dynamics-based PA interventions. The first iteration of the trial design was to compare individual $\mathrm{v}$ group based incentives to add to the current body of literature; hypothesizing that in a group based intervention, working towards group goals (and compensation based on group goals) may be more effective. When the design was then changed to examine the potential effectiveness of a group dynamics based intervention specific to Black, college women with a matched

Table 4.

Variables measured during IMA DIVA and time period measures.

\begin{tabular}{|c|c|c|c|}
\hline Variables & Baseline & Post program & 3-month follow up \\
\hline Demographics & $\mathrm{X}$ & & \\
\hline Health-related quality of life (HRQOL) & $\mathrm{X}$ & $\mathrm{X}$ & $\mathrm{X}$ \\
\hline Self-reported physical activity (PA) & $\mathrm{X}$ & $\mathrm{X}$ & $\mathrm{X}$ \\
\hline Physical activity self-efficacy (PASE) & $\mathrm{X}$ & $\mathrm{X}$ & $\mathrm{X}$ \\
\hline Physical activity self-regulation (PASR) & $\mathrm{X}$ & $\mathrm{X}$ & $\mathrm{X}$ \\
\hline Group similarities (GS) & $\mathrm{X}$ & $\mathrm{X}$ & $\mathrm{X}$ \\
\hline \multicolumn{4}{|l|}{ Group dynamics (GD) measures to include: } \\
\hline Individual attraction to group task (ATGT) & $\mathrm{X}$ & $\mathrm{X}$ & $\mathrm{X}$ \\
\hline Individual attraction to group socially (ATGS) & $\mathrm{x}$ & $\mathrm{x}$ & $\mathrm{X}$ \\
\hline Group’s integration toward the task (GIT) & $\mathrm{X}$ & $\mathrm{X}$ & $\mathrm{X}$ \\
\hline Group’s integration socially (GIS) & $\mathrm{x}$ & $\mathrm{x}$ & $\mathrm{X}$ \\
\hline Group’s communication (COMM) & $\mathrm{X}$ & $\mathrm{X}$ & $\mathrm{X}$ \\
\hline Group’s competition (COMP) & $\mathrm{x}$ & $\mathrm{X}$ & $\mathrm{X}$ \\
\hline Group’s cooperation (COOP) & $\mathrm{X}$ & $\mathrm{X}$ & $\mathrm{X}$ \\
\hline Objectively measured PA, by accelerometer & $\mathrm{X}$ & $X$ & $X$ \\
\hline
\end{tabular}

Table 5.

Physical activity outcomes.

\begin{tabular}{ccccccc}
\hline & \multicolumn{2}{c}{ Baseline } & \multicolumn{2}{c}{ Post-Program } & \multicolumn{2}{c}{ Follow-Up } \\
\hline & Control & Enhanced & Control & Enhanced & Control & Enhanced \\
Moderate only & $57.3(71.8)$ & $63.0(68.9)$ & $147.6(483.7)$ & $202.7(564.7)$ & $62.9(73.3)$ & $119.2(124.9)$ \\
Vigorous only & $119.0(196.4)$ & $87.5(84.7)$ & $87.3(159.5)$ & $63.7(59.4)$ & $37.4(64.7)$ & $19.6(109.3)$ \\
Moderate and vigorous & $176.3(235.2)$ & $150.5(138.3)$ & $234.9(487.7)$ & $266.3(587.5)$ & $100.3(107.5)$ & $198.8(180.3)$ \\
Strength training & $17.7(37.7)$ & $35.3(54.7)$ & $12.1(27.9)$ & $10.3(19.1)$ & $22.1(48.1)$ & $34.6(70.1)$ \\
\hline
\end{tabular}

${ }^{*}$ Minutes mean (SD), based on self-report measures, stratified by group randomization. 
contact control, the intent of the study changed entirely. Evident in this manuscript, however, is that the organic climate of the control group led to yet another variation in the research design. The end result was a trial that compared group dynamics delivered to small groups $(n=5)$ versus a larger cohort $(n=$ 25). Further still, the varying attendance rates of the small groups led to the need for further investigation before definitive conclusions can be made on appropriate group composition for this population.

The second largest changes were seen in the intended and delivered data analysis. As increasing minutes of PA was the primary specific aim of the intervention, it seemed most plausible to obtain PA duration at baseline, post-program and followup through both self-report (i.e., Godin) and objective measures (i.e., tri-axel accelerometers). Two lessons learned here: first, the women were not insufficiently active at baseline and, two, self-report did not highly correlate to objective outcome measures. As for the latter, it is opposite from what typically happens in the literature. Participants tend to overestimate their activity levels (Adams et al., 2005). Yet, participants in IMA DIVA were more active according to their accelerometer read outs than their own self-report of PA. And, finally, the demographic screener distributed during recruitment did not measure participants' baseline PA levels. This lead to the recruitment of sufficiently active women that make it harder to detect an increase in PA over the 8 week program.

In addition, the collaborative effort set forth by the students allowed a needed balance between leadership and followership (DeVore \& Hyatt, 2010). Each member of the team had a specific role and associated responsibilities. Role clarity was established and agreed upon within a preliminary team meeting. When members are unaware of their roles or have unfulfilled expectations, they tend to have negative group outcomes including frustration and mistrust (Hare \& O'Neil, 2000). Distinct roles allow the unique talents of individuals to contribute to successfully accomplishing the group's task. When role expectation is clear, individuals feel accountable and confident in their position within the group. Role clarity and acceptance leads to greater satisfaction and cohesion (Carron, Colman, Wheeler, \& Stevens, 2002). Additionally, millennials (students born post-1982) are criticized that while their social networks may be in the upper hundreds, they lack the ability to understand conflict resolution and to assess opinions of others (Phlan, 2011). Contrary to this criticism, the research team actively engaged in opinion assessment and acknowledgment of different strengths in each other as researchers. The research team, like all groups, exhibited a distinct culture guided by shared values, beliefs, and norms (Sanchez \& Yurrebaso, 2009). The common goal for implementing a successful intervention was only one common thread among the young investigators, while the desire to have a public health impact, increase PA for a health disparate population, and changing lives were underlying goals.

There is also a call for pedagogical practices to initiate programs and coursework that produce students who value diversity and do not engage in damaging biases (i.e., racism, sexism, ableism; Rovengo, 2008). Since this project had both a racially diverse research team (e.g., African-American, Caucasian, and Asian) and target population (i.e., females of African descent), the research team had to engage in cultural humility. Cultural humility promotes self-evaluation and self-critique that aims to be open and acknowledge differences rather than claiming cul- tural competence, which is an unobtainable endpoint (Israel, Eng, Schulz, \& Parker, 2005).

The research team also gained confidence in their ability to successfully deliver an evidence-based program as IMA DIVA was founded on tenets of group dynamics. While there is not a standard package of group dynamics strategies applied across the literature (Estabrooks, Harden, \& Burke, 2012), the research team reviewed the current literature for appropriate set of strategies to guide the design and development of a program manual for the intervention. While making real-world adaptations was a challenge, the researchers aimed to adhere to underlying program principles and record any variations from the manual. The lessons learned throughout this process equipped the five junior researchers with experiential knowledge to increase the likelihood of success in their next funding opportunity.

\section{Conclusion}

Graduate students often find themselves within a (fairly narrow, time-constrained) research niche. This project brought together five research scientists with varying levels of intervention experience and expertise. While the $a$ priori hypothesis of the intervention was not supported (i.e., minutes of PA did not increase throughout the project), the research team gained invaluable skills for future health promotion programs and real-world grant applications for prospective NIH K, R03 and R21 or non-profit grants as young researchers. Phlan (2011) calls to educate students in such a way that they can interact properly within a complex, and multidisciplinary job market upon graduation; this paper provides support for a graduate student competitive project that has the potential to utilize skills fostered in an immeasurable experiential learning opportunity for future career development.

\section{Acknowledgements}

The authors would like to acknowledge their mentors Drs. Fabio Almeida, Paul Estabrooks, Jennie Hill, and Jamie Zoellner for providing us with this valuable experiential learning opportunity. We would like to thank Blake Krippendorf, Susie Choi, and Shannon Summers and the other undergraduate research assistants for their contributions during the project. We would also like to acknowledge the competitive Translational Obesity Research Program Fellowship that funded this research project.

\section{REFERENCES}

Adams, S. A., Matthews, C. E., Ebbeling, C. B., Moore, C. G., Cunningham, J. E., Fulton, J., \& Hebert, J. R. (2005). The effect of social desirability and social approval on self-reports of physical activity. American Journal of Epidemiology, 161, 389-398. doi:10.1093/aje/kwi054

Anderson, E. S., Wojcik, J. R., Winett, R. A., \& Williams, D. M. (2006). Social-cognitive determinants of physical activity: The influence of social support, self-efficacy, outcome expectations, and self-regulation among participants in a church-based health promotion study. Health Psychology, 25, 510-520. doi:10.1037/0278-6133.25.4.510

Barnett, R., \& Coate, K. (2005). Engaging the curriculum in higher education. Buckingham: SRHE and Open University Press.

Beauchamp, M., Dunlop, W. L., Downey, S. M., \& Estabrooks, P. A. (2012). First impressions count: Perceptions of surface-level and 
deep-level similarity within postnatal exercise classes and implications for program adherence. Journal of Sport \& Exercise Psychology, 17, 68-76.

Berg, K. M., Thomas, M. G., Brown, A. F., Zerzan, J., Elmore, J. E., \& Wilson, I. B. (2007) Demystifying the NIH grant application process. Journal of General Internal Medicine, 22, 1587-1595. doi:10.1007/s11606-007-0301-6

Bransford, J. D., Brown, A. L., \& Cocking, R. R. (2000). How people learn: Brain, mind experience, and school. Washington DC: National Academy Press.

Carron, A. V., Colman, M. M., Wheeler, J., \& Stevens, D. (2002). Cohesion and performance in sport: A meta analysis. Journal of Sport \& Exercise Psychology, 24, 168.

Carron, A. V., \& Spink, K. S. (1993). Team building in an exercise setting. The Sport Psychologist, 7, 8-18.

Carron, A. V., Widmeyer, W. N., \& Brawley, L. R. (1985). The development of an instrument to assess cohesion in sport teams: The Group Environment Questionnaire. Journal of Sport Psychology, 7, 244-266.

Center for Disease Control (2012) How much physical activity do adults need? URL (last checked 23 January 2012).

http://www.cdc.gov/physicalactivity/everyone/guidelines/adults.html

DeVore, D., \& Hyatt, L. (2010). Using the ECO-Model to teach organizational change to graduate and post-graduate students. The International Journal of Learning, 17, 485-492.

Dewey, J. (1897). My pedagogic creed. The School Journal, 54, 77-80.

Doak, C. M., Visscher, T. L. S., Renders, C. M., \& Seidell, J. C. (2006). The prevention of overweight and obesity in children and adolescents: A review of interventions and programmes. Obesity Reviews, 7, 111136.

Dzewaltowski, D. A, Estabrooks, P. A., \& Glasgow, R. E. (2004). The future of physical activity behavior change research: What is needed to improve translation of research into health promotion practice? Exercise Sport Science Review, 32, 57-63. doi:10.1097/00003677-200404000-00004

Estabrooks, P. A. (2000). Sustaining exercise participation through group cohesion. Exercise and Sport Sciences Review, 28, 63-67.

Estabrooks, P. A., \& Carron, A. V. (2000). The physical activity group environment questionnaire: And instrument for the assessment of cohesion in exercise class. Group Dynamics: Theory, Research and Practice, 4, 230-243. doi:10.1037/1089-2699.4.3.230

Estabrooks, P. A., Harden, S. M., \& Burke, S. M. (2012). Group dynamics in physical activity interventions: What works? Social and Personality Psychology Compass, 6, 18-40. doi:10.1111/j.1751-9004.2011.00409.x

Fogg, B. J. (2009). A behavior model for persuasive design. Persuasive 09: Proceedings of the 4th International Conference on Persuasive Technology, New York, 1-7.

Freedson, P. S., Melanson, E., \& Sirard, J. (1998). Calibration of the Computer Science and Applications, Inc. accelerometer. Medicine \&
Science in Sports \& Exercise, 30, 777-781. doi:10.1097/00005768-199805000-00021

Gaff, J. G. (2002). The disconnect: Graduate education and faculty realities: A review of recent research. Liberal Education, 88, 6-13.

Godin, G., \& Shephard, R. J. (1985). A simple method to assess exercise behavior in the community. Canadian Journal of Applied Sport Sciences, 10, 141-146.

Golembiewski, R. T. (1962). The small group: An analysis of research concepts and operations. Chicago: University of Chicago Press.

Hanrahan, S. J., \& Isaacs, G. (2001). Assessing self- and peer-assessment: The students' views. Higher Education Research \& Development, 20, 53-70. doi:10.1080/07294360123776

Hare, L. R., \& O'Neill, K. (2000). Effectiveness and efficiency in small academic peer groups: A case study. Small Group Research, 31, 2453. doi:10.1177/104649640003100102

Israel, B. A., Eng, E., Schulz, A. J., \& Parker, E. A. (2005). Methods in community-based participatory research for health. San Francisco, CA: Jossey-Bass.

Lott, A. J., \& Lott, B. E. (1965). Group cohesiveness as interpersonal attraction: A review of relationships with antecedent and consequent variables. Psychological bulletin, 64, 259-309. doi:10.1037/h0022386

Moore, A. H., Fowler, S. B., \& Watson, C. E. (2007). Active learning and technology: Designing change for faculty, students, and institutions. Educause Review, 42, 42-61.

Moore, M., Tatum, B. C., Sebetan, I. (2011). Graduate education: What matters most? Journal of Research in Innovative Teaching, 4, 65-77.

National Science Foundation (2012). NSF at a glance. URL (last checked 12 February 2012). http://www.nsf.gov/about/glance.jsp

Phlan, P. (2011). Building the 21st century curriculum. BizEd, Special Focus, 38-45.

Rovengo, I. L. (2008). Learning and instruction in social, cultural environments: Promising research agendas. Quest, 60, 84-104. doi:10.1080/00336297.2008.10483570

Sanchez, J. C., \& Yurrebaso, A. (2009). Group cohesion: Relationships with work team culture. Psicothema, 21, 97-104.

Sasaki, J. E., John, D., \& Freedson, P. S. (2011). Validation and comparison of ActiGraph activity monitors. Journal of Science and Medicine in Sport, 14, 411-416. doi:10.1016/j.jsams.2011.04.003

Trost, S. G., Loprinzi, P. D., Moore, R., \& Pfeiffer, K. A. (2011). Comparison of accelerometer cut points for predicting activity intensity in youth. Medicine \& Science in Sports \& Exercise, 43, 1360-1368. doi:10.1249/MSS.0b013e318206476e

Tsang, A. K. L. (2011). Online reflective group discussion-Connecting first year undergraduate students with their third year peers. Journal of the Scholarship of Teaching and Learning, 11, 58-74.

US Department of Health and Human Services (2011). NIH Budget. URL (last checked 2 March 2012).

http://www.nih.gov/about/budget.htm 